\title{
Percutaneous Aortic Valve Replacement
}

National Cancer Institute

\section{Source}

National Cancer Institute. Percutaneous Aortic Valve Replacement. NCI Thesaurus. Code C80448.

A procedure performed to replace a narrowed and calcified aortic valve in patients unable to withstand open chest surgery. A bioprosthesis is advanced through the vessels with a catheter up to the diseased native aortic valve. Once the catheter is positioned in the opening of the aortic valve it releases the bioprosthesis at the mid part of the aortic valve. 